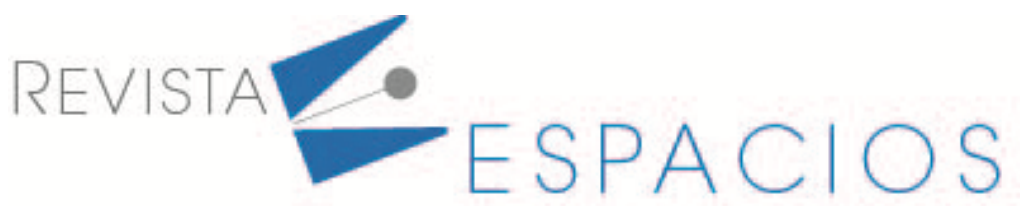

\title{
Seguridad alimentaria y nutricional en los cantones de la provincia de Chimborazo - Ecuador
}

\section{Food and nutritional security in the cantons of the province of Chimborazo - Ecuador}

\author{
PERALTA, Lilia O. ${ }^{1}$ \\ MEJÍA, Martha C. ${ }^{2}$ \\ GAVIDIA, Mayra A. ${ }^{3}$ \\ GRANIZO, Ángela V. ${ }^{4}$
}

\begin{abstract}
Resumen
La investigación sobre seguridad alimentaria fue llevada a cabo en 155 familias del sector rural en Chimborazo, Ecuador. El problema identificado fue la inseguridad alimentaria que responde a problemas de los componentes disponibilidad, acceso, uso, estabilidad en la oferta alimentaria e institucionalidad. Estos problemas se evidenciaron en indicadores sociales, económicos, culturales; pero sobre todo, en indicadores de salud de la población en general y de los grupos vulnerables en particular, como deficiencia en consumo y uso de los alimentos y sus respectivas secuelas.

Palabras clave: Condiciones socioeconómicas, disponibilidad, acceso y uso de alimentos
\end{abstract}

\begin{abstract}
The research on food security was carried out in 155 families in the rural sector in Chimborazo. The problem identified was food insecurity, which responds to problems in the components of availability, access, use, stability of food supply and institutionalism. These problems were evidenced in social, economic and cultural indicators, but above all, in health indicators of the population in general and of vulnerable groups in particular, such as deficiency in consumption and use of food and their respective consequences.
\end{abstract}

Key words: Socioeconomic conditions, food availability, access and use

\section{Introducción}

En la Cumbre Mundial de la Alimentación (CMA) de 1996, la Organización de las Naciones Unidas para la Agricultura y la Alimentación (FAO), expresó que la Seguridad Alimentaria se consigue "cuando todas las personas, en todo momento, tienen acceso físico y económico a suficiente alimento, seguro y nutritivo, para satisfacer sus necesidades alimenticias y sus preferencias, con el objeto de llevar una vida activa y sana" y en

\footnotetext{
${ }^{1}$ Docente Carrera Nutrición y Dietética. Facultad de Salud Pública. Escuela Superior Politécnica de Chimborazo. Ecuador. lilia.peralta@espoch.edu.ec. 2 Docente Maestría de Nutrición Infantil. Instituto de Posgrado. Escuela Superior Politécnica de Chimborazo. Ecuador. martha.mejia@espoch.edu.ec.

${ }^{3}$ Docente Carrera Nutrición y Dietética. Facultad de Salud Pública. Escuela Superior Politécnica de Chimborazo. Ecuador. mayra.gavidia.c@gmail.com

${ }^{4}$ Técnico Docente Titular. Laboratorio de Informática Facultad de Salud Publica. Escuela Superior Politécnica de Chimborazo. Ecuador agranizo@espoch.edu.ec.
} 
consonancia con el derecho fundamental de no padecer hambre (Calero León, 2011; Programa Especial para la Seguridad Alimentaria-PESA-Centroamérica. Proyecto Food Facility Honduras, 2011).

Luego de los compromisos adquiridos en esta Cumbre, Ecuador asumió el reto de fortalecer la Seguridad Alimentaria y Nutricional estableciendo en 1998 el Decreto Ejecutivo 1039 que declara a la Seguridad Alimentaria como Política de Estado, sin embargo, no es posible rescatar dentro de los planes, propuestas y proyectos planificados, acciones realmente transcendentes en favor de la seguridad alimentaria del país (Ministerio de Coordinación de Desarrollo Social. FAO, 2011). Posteriormente, la Constitución Política de 2008 en su artículo 13 estableció que "las personas y colectividades tienen derecho al acceso seguro y permanente a alimentos sanos, suficientes y nutritivos; preferentemente producidos a nivel local y en correspondencia con sus diversas identidades y tradiciones culturales" en acuerdo a FAO, 2018. Un avance constituyó, dentro de las políticas promulgadas, la Ley Orgánica del Régimen de la Soberanía Alimentaria (febrero 2009), creada con la finalidad de establecer mecanismos para que el Estado garantice a las personas, comunidades y pueblos la autosuficiencia de alimentos sanos, nutritivos y culturalmente apropiados de forma permanente, la cual deja sin efecto los artículos de la Ley No. 41 de Seguridad Alimentaria Nutricional (Ministerio de Coordinación de Desarrollo Social. FAO, 2011).

En el contexto de la Seguridad Alimentaria, en 1996, en la CMA se estableció como uno de los objetivos "erradicar el hambre en todos los países, reducir el número de personas desnutridas a la mitad de su nivel actual y todo esto hasta el año 2015". Posteriormente en el año 2000, uno de los Objetivos del Desarrollo del Milenio (Declaración del Milenio) promovió "reducir a la mitad entre 1990 y 2015 el porcentaje de personas que padecen hambre" (FAO, 2020). A pesar de los esfuerzos realizados por los países este objetivo no se ha cumplido, por lo que la Agenda 2030 para el Desarrollo Sostenible ha replanteado la manera cómo erradicar la pobreza y el hambre con un límite definido de 15 años. Para ello se insta a todos los países (ricos o pobres) a trabajar a través de alianzas para transformar las condiciones de vida de los grupos de población más vulnerable (FAO, 2021). Sin embargo, estas metas no podrán alcanzarse mientras muchas poblaciones de la región de las Américas sigan viviendo en pobreza y extrema pobreza, con altos niveles de desnutrición, sin oportunidades económicas, sin servicios públicos adecuados y eventos climáticos severos.

Estadísticas en América Latina y el Caribe muestran que durante 2019, 7,4\% de su población vivió con hambre, es decir 47,7 millones de personas, la población afectada por inseguridad alimentaria ha ido en aumento en los últimos cinco años, en este mismo año 191 millones de personas, se vieron afectadas por inseguridad alimentaria moderada o grave. De ellos, 57,7 millones, aproximadamente un 10\% de la población de la región, se vio en situación de inseguridad alimentaria grave, es decir, se quedaron sin alimentos, pasaron hambre o estuvieron más de un día sin comer (FAO. FIDA. OPS. WFP y UNICEF, 2020).

A pesar de que la desnutrición crónica infantil (retardo en crecimiento T/E) en América Latina y el Caribe ha mostrado ciertos avances, disminuyendo de $24,5 \%$ en 1990 a 11,3\% en 2015, lo que representa una reducción de 7,8 millones de niños; actualmente 6,1 millones aún viven con desnutrición crónica: 3,3 millones en Sudamérica, 2,6 millones en Centroamérica y 200 mil del Caribe, 700 mil niños y niñas sufren desnutrición aguda. La desnutrición afecta a la población más pobre y a las zonas rurales en todos los países. Las prevalencias más altas de desnutrición crónica infantil en la región se pueden observar en Guatemala y Ecuador, mientras que Chile y Santa Lucía tienen las menores tasas (OPS/OMS, 2020).

En el Ecuador, a junio de 2018, la pobreza a nivel nacional se ubicó en 24,5\% y la pobreza extrema en 9,0\%, siendo el área rural en donde la pobreza es más considerable alcanzando el 43,0\%, (INEC, 2014). En relación a los niveles de desnutrición, al menos 1 de cada 5 niños menores de cinco años tiene baja talla para la edad es decir retardo en crecimiento. El 12\% de los niños tiene desnutrición global (bajo peso para la edad). El 16\% nacen 
con bajo peso. Seis de cada 10 embarazadas y 7 de cada 10 menores de 1 año sufren de anemia por deficiencia de hierro. Las poblaciones rurales y específicamente el sector indígena es un grupo en condición de pobreza, lo cual se refleja en la alta prevalencia de retardo en talla, aproximadamente dos veces más alta $(42,3 \%$,) comparada con los otros grupos étnicos (Freire et al., 2013), es así que en Chimborazo, con alta población indígena, la desnutrición alcanza un 44\% mientras el promedio nacional es de 19\%. Estos son algunos indicadores que muestran la gravedad del problema y la urgencia de incrementar esfuerzos para combatirlos (Observatorio Social del Ecuador, 2019).

Paradójicamente, el problema en Ecuador no es la falta de disponibilidad de alimentos, es la inequidad en el acceso a una alimentación adecuada que tiene como causas factores educativos y económicos. A la causa inmediata de dificultades en la alimentación se suman las infecciones y enfermedades, bajo acceso a la educación, principalmente de la madre, a educación nutricional, a servicios de salud y brechas en el acceso a agua y saneamiento. Dentro de las causas estructurales se encuentran el bajo ingreso, la pobreza y la débil aplicación del marco legal y de las políticas públicas.

Ecuador es un país que debido a la situación geográfica y a la diversidad de clima, altitud, pluviosidad y diversidad de culturas existen las condiciones adecuadas para la producción de todos los alimentos básicos y necesarios que se incluyen en la distribución de los grupos de alimentos, que por razones de mayor entendimiento se sigue utilizando la Pirámide Alimentaria. Sin embargo, a pesar de este panorama del país, a nivel de los hogares persiste la tendencia a que las existencias de alimentos sean 2.4 veces mayores en el $10 \%$ de los hogares más ricos que en el $10 \%$ de los más pobres (Ramírez \& Ramírez Gallegos, 2002).

La falta de disponibilidad de los alimentos debido a la dificultad de producción, acceso a la tierra para sembrar y las condiciones de extrema competitividad en el mercado tanto local, nacional como internacional y la dificultad al acceso o compra de alimentos por la falta de empleo, subempleo y salarios bajos, son consideradas causas de inseguridad alimentaria y nutricional en la mayoría de países del mundo. En el Ecuador, aunque la lucha contra la pobreza y el hambre ha sido un discurso constante más de los aspirantes a líderes que una vez gobernantes, aun se espera que se efectivice la garantía de movilización de recursos de fuentes públicas y privadas, que se instaure de manera efectiva la cooperación para el desarrollo, para proporcionar medios suficientes para las comunidades más afectadas a fin de poner fin a todas las formas de pobreza.

El presente estudio como antesala a las actividades de vinculación pretende trabajar en los factores asociados a los componentes de la seguridad alimentaria, permitiendo a las personas tener una visión más amplia de cómo asegurar su alimento diario en cantidad y calidad suficiente y en acuerdo a las necesidades de los miembros de la familia. Además de garantizarles la energía indispensable para el trabajo, el estudio y, el bienestar general. Independientemente del nivel educativo de los individuos aprovechar la oportunidad de adquirir conocimientos que generen comportamientos hacia la salud, higiene y alimentación es la mejor opción de vida.

\section{Metodología}

El estudio tuvo un enfoque cuali-cuantitativo de diseño no experimental y transversal; se utilizó como técnica la aplicación de una encuesta a una muestra de 155 familias de las parroquias rurales del Cantón Riobamba, aplicándose a los jefes de familia quienes colaboraron en su gran mayoría con el acercamiento a través de los Presidentes de las Juntas Parroquiales. Los jefes de familia fueron apropiadamente informados sobre el objetivo del estudio y firmaron el consentimiento para su participación. Los resultados fueron revisados y codificados en acuerdo al peso que se daría a cada una de las variables. Se elaboró la base de datos en EXCEL, para el análisis descriptivo, se utilizó el programa SPSS versión 23. Las variables estudiadas fueron agrupadas de acuerdo con 
factores socioeconómicos y de componentes de la seguridad alimentaria como se describe a continuación (ver tabla 1):

Tabla 1

Variables de estudio de acuerdo a factores socioeconómicos y seguridada alimentaria

\begin{tabular}{|c|c|}
\hline CARACTERÍSTICAS SOCIOECONÓMICAS & $\begin{array}{l}\text { Tipología familiar } \\
\text { Número } \\
\text { Parentesco } \\
\text { Sexo } \\
\text { Edad } \\
\text { Escolaridad de la madre } \\
\text { Ocupación principal del jefe de hogar }\end{array}$ \\
\hline ÍNDICE DE RIESGO DE VIVIENDA & $\begin{array}{l}\text { Número de personas que habitan en el hogar } \\
\text { Número de dormitorios de la vivienda } \\
\text { Material del piso de la vivienda } \\
\text { Acceso a agua segura } \\
\text { Disponibilidad de servicios higiénicos } \\
\text { Acceso a alcantarillado } \\
\text { Recolección de basura } \\
\text { Ubicación de la cocina }\end{array}$ \\
\hline ACCESO A SERVICIOS & $\begin{array}{l}\text { Ducha para bañarse } \\
\text { Internet } \\
\text { Teléfono celular } \\
\text { Radio } \\
\text { Gas } \\
\text { Teléfono convencional } \\
\text { Luz eléctrica } \\
\text { Televisión }\end{array}$ \\
\hline DISPONIBILIDAD DE ALIMENTOS & $\begin{array}{l}\text { Producción } \\
\text { Destino } \\
\text { Comercialización }\end{array}$ \\
\hline DESTINO DE LA PRODUCCIÓN & $\begin{array}{l}\text { Procesamiento } \\
\text { Venta } \\
\text { Autoconsumo }\end{array}$ \\
\hline ACCESO A LOS ALIMENTOS & $\begin{array}{l}\text { Prácticas alimentarias } \\
\text { Consumo diario según grupos de alimentos } \\
\text { Tiempos de comida } \\
\text { Consumo de bebidas } \\
\text { Consumo de agua pura } \\
\text { Formas de preparación de alimentos } \\
\text { Comidas fuera del hogar } \\
\text { Forma de almacenamiento de alimentos en casos de } \\
\text { emergencia }\end{array}$ \\
\hline USO DE ALIMENTOS & $\begin{array}{l}\text { Condiciones de salud } \\
\text { Enfermedades prevalentes y condiciones de discapacidad } \\
\text { Higiene personal, familiar y comunitaria } \\
\text { Atención en salud } \\
\text { Morbi - mortalidad }\end{array}$ \\
\hline FACTORES ALIMENTARIOS & $\begin{array}{l}\text { Destete } \\
\text { Alimentación complementaria } \\
\text { Alimentación con biberón } \\
\text { Edad de introducción de leche de vaca }\end{array}$ \\
\hline $\begin{array}{l}\text { ESTABILIDAD EN EL ACCESO A LOS } \\
\text { ALIMENTOS }\end{array}$ & $\begin{array}{l}\text { Épocas de escasez de alimentos } \\
\text { Gestión de acceso en casos de escasez } \\
\text { Abuso razonable } \\
\text { Semáforo nutricional }\end{array}$ \\
\hline
\end{tabular}

\section{Resultados y discusión}

\subsection{Características socioeconómicas}

Las características socioeconómicas de una población pueden ser factores contribuyentes al bienestar de las familias; en condiciones ideales, que el rol de jefe de hogar sea cumplido por una persona de género masculino, 
podría representar una mejor condición económica, de seguridad, de afecto y protección; en la población estudiada el $80 \%$ identificaron como jefes de hogar a personas de este género. En dependencia de la calidad y cobertura del sistema de educación de un país, se consideraría como un factor relevante que toda la población, especialmente el de las personas de género femenino, alcance el mayor nivel de educación que sea posible por la incidencia materna en el cuidado de la familia; $y$, si bien es cierto que cada vez se incrementa el número de mujeres asistiendo a los sistemas educativos formales, aun es menor en los sectores rurales (Rodríguez Garcés \& Muñoz Soto, 2016). En el gráfico 1 se observa que un 74\% de las madres han alcanzado niveles escolares de primaria o secundaria, sin embargo, el porcentaje de las personas sin instrucción supera al de instrucción superior (ver gráfico 1).

Gráfico 1

Escolaridad de la madre

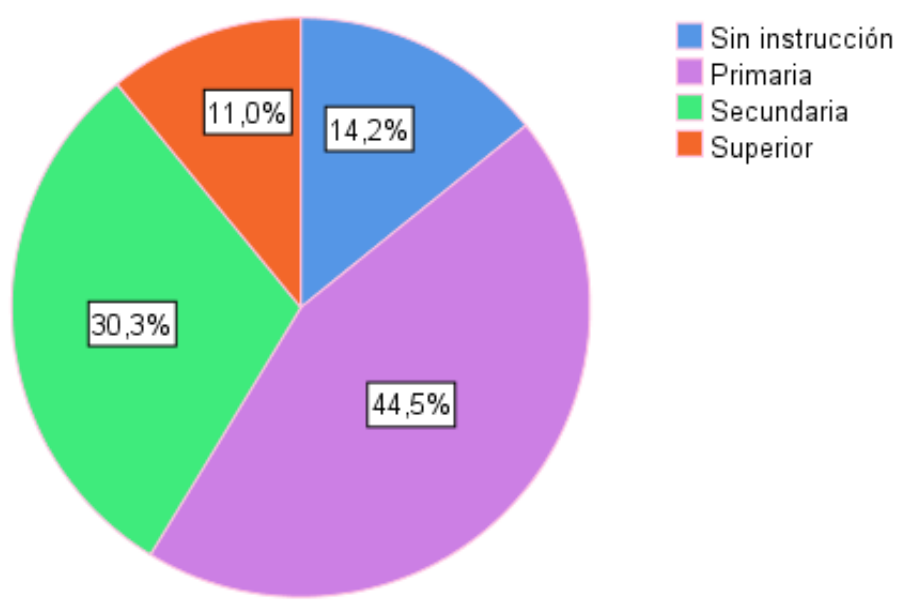

El estudio al ser realizado en el sector rural, el mayor porcentaje respondió que los jefes de hogar eran agricultores, con un bajo porcentaje (3.87) como amas de casa; 3 de cada 10 con negocio propio, relacionado éste con actividades de comercialización de los productos de su actividad agrícola y/o pecuaria (ver gráfico 2).

Gráfico 2

Ocupación del jefe de hogar

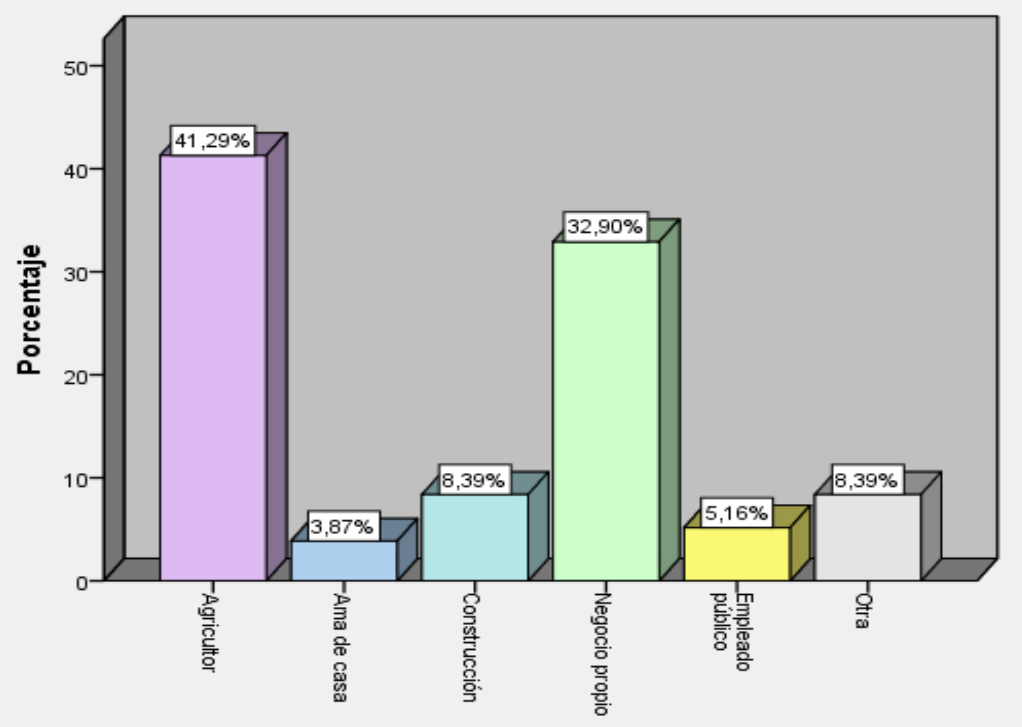


Otro de los indicadores que se han ido modificando a través del tiempo, es el promedio de habitantes por vivienda, no solo por el número sino por la relaciones intrafamiliares y externas que explican los cambios que pueden haberse operado. En este estudio se encontró que la gran mayoría, alrededor del $80 \%$ de las familias estaban compuestas entre 2 y 6 miembros, con un promedio de 4 miembros por familia.

Para construir el índice de riesgo de vivienda, se indagó sobre el número de habitaciones utilizadas como dormitorios, y se encontró que el $85 \%$ de la relación personas - dormitorio, correspondía de 3 a 4, con una mediana de 3. En cuanto al tipo de material del piso de la vivienda, la mayor parte $(69.7 \%)$ era de cemento $(30.0 \%$ de madera) y el resto de tierra o vinil.

También es usual encontrar una brecha entre los servicios básicos en los sectores urbanos, en contraste con los rurales. Estos últimos, generalmente por la desconcentración geográfica requieren de una inversión económica mayor o dificultades para proveer a la población de dichos servicios. Más del 70\% de la población estudiada dispone de agua potable y alcantarillado, porcentaje que se puede explicar debido a que la investigación fue realizada en su mayor parte en las cabeceras parroquiales. Más del $90 \%$ de las familias investigadas contaban con servicio higiénico y la cocina era un ambiente separado del resto de la vivienda como se presenta en el gráfico 3.

Gráfico 3

Nivel de acceso a servicios básicos

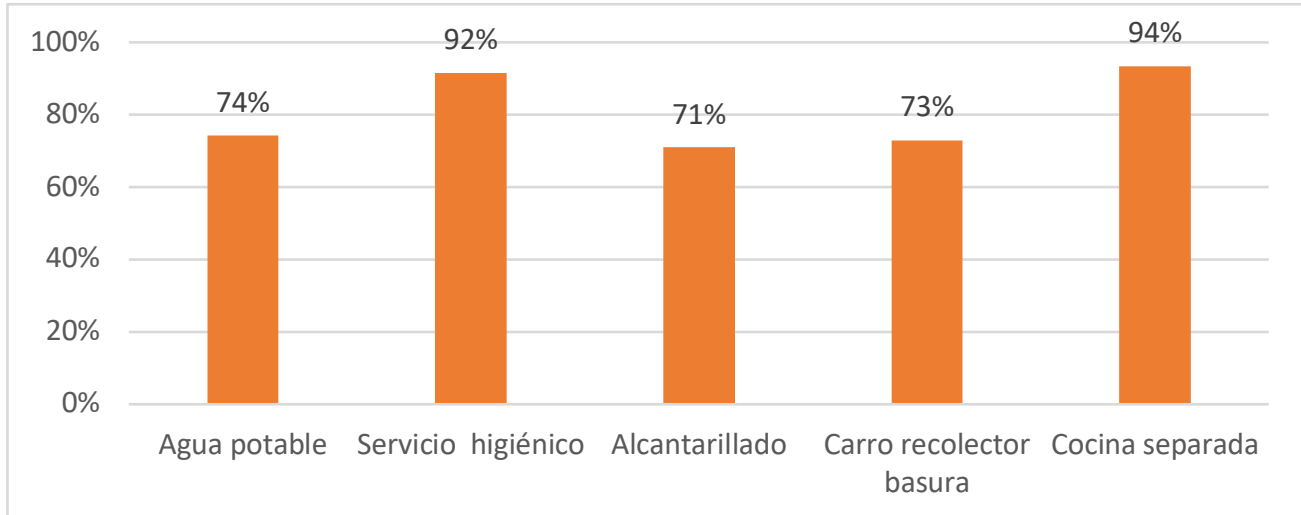

Todas las variables estudiadas sobre la vivienda, permitieron llegar a la siguiente tabla 2 en donde se observa que, la gran mayoría, se encuentra en mediano riesgo, significando que uno o varios elementos faltan para alcanzar un mayor nivel de seguridad en la salud de sus habitantes, tales como número de dormitorios en relación al número de miembros de la familia, el material de construcción o servicios básicos de agua, alcantarillado u otros.

Tabla 2

Índice de riesgo de vivienda

\begin{tabular}{llrrrr}
\hline \multicolumn{1}{l}{ Nivel de riesgo } & Frecuencia & Porcentaje & \multicolumn{1}{c}{$\begin{array}{c}\text { Porcentaje } \\
\text { válido }\end{array}$} & $\begin{array}{c}\text { Porcentaje } \\
\text { acumulado }\end{array}$ \\
\hline Válido & Bajo riesgo & 7 & 4,5 & 4,5 & 4,5 \\
\cline { 2 - 6 } & Mediano riesgo & 135 & 87,1 & 87,1 & 91,6 \\
\cline { 2 - 6 } & Alto riesgo & 13 & 8,4 & 8,4 & 100,0 \\
\cline { 2 - 6 } & Total & 155 & 100,0 & 100,0 & \\
\hline
\end{tabular}


No tener acceso en las parroquias rurales a servicios tales como ducha, luz, gas, hace unas décadas, podría haber parecido algo cotidiano, no disponer de éstos actualmente, supone un vacío administrativo relacionado con el estado de bienestar de la población y una carga para el ambiente, porque el medio de adquisición de energía seguirá siendo el carbón o la leña. Por otro lado, no disponer de medios de comunicación habla de situaciones de aislamiento. Del acceso a todos los servicios mencionados los porcentajes más bajos encontrados son duchas para el aseo personal e internet como medio masivo de comunicación (ver gráfico 4).

Gráfico 4

Acceso a otros servicios

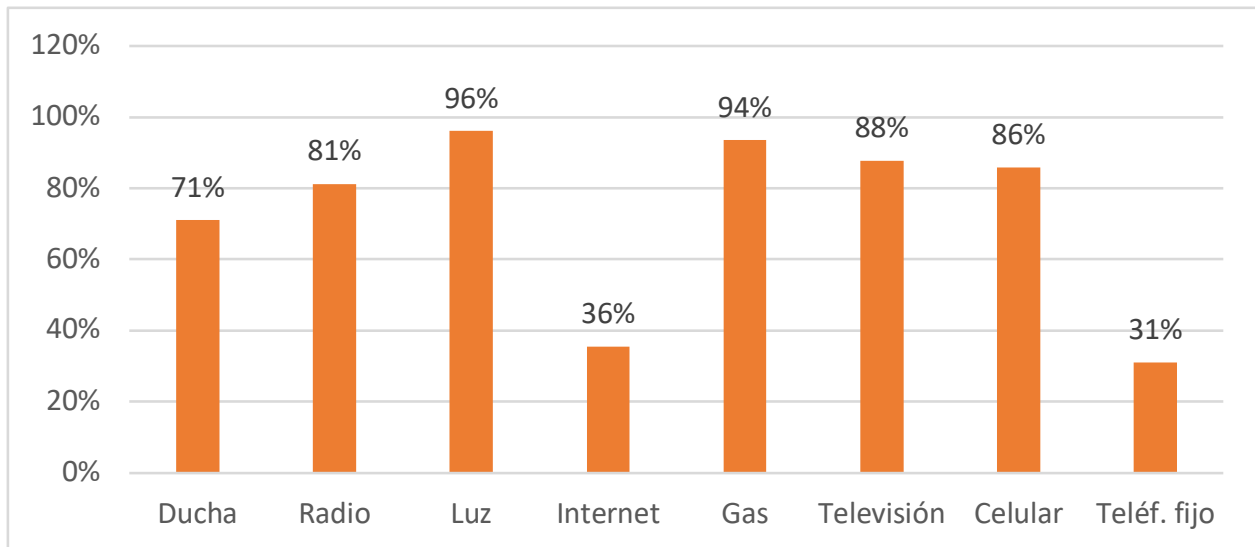

La relación del acceso a otros servicios permitió identificar que alrededor del $40 \%$ de las familias tenían un nivel medianamente adecuado o inadecuado que podría constituir un determinante en los niveles de bienestar de la población.

\subsection{Disponibilidad de alimentos}

Uno de los objetivos de presente estudio fue identificar algunos factores relacionados con la disponibilidad de alimentos en la población investigada, tales como producción, destino de la misma, lugares de abastecimiento y, si reciben algún tipo de ayuda alimentaria. La posibilidad de contar con un mercado bien estructurado y cercano al sitio de las viviendas, trae la ventaja de acceder a una gran variedad, calidad y buen estado de los alimentos; seguramente a menor costo y, que no conlleve a un encarecimiento de los mismos por el costo de transporte. Se encontró que el $72,3 \%$ realizaba sus compras en cabeceras cantonales. En cuanto a si sus familias son beneficiarias de algún tipo de ayuda alimentaria, el 93\% por ciento, respondió que no; y, el 75\% manifestó que producen algún tipo de alimento y/o crían animales para destino alimentario.

La producción de alimentos, independientemente del volumen, en las familias investigadas según los resultados tenían uno o varios tipos de legumbres, verduras, cereales, tubérculos o frutas, como producción agrícola; en cuanto a la producción pecuaria, aves, leche, huevos y, criaban algunas especies menores, especialmente cuyes y otras mayores como borregos, cerdos o ganado vacuno. El destino de la producción se agrupó en siete categorías: procesamiento, venta, autoconsumo, procesamiento y venta, procesamiento y autoconsumo, venta y autoconsumo, procesamiento, venta y autoconsumo (ver gráfico 5).

1. Procesamiento: Fue uno de los porcentajes más bajos, realizando labores mínimas como embalaje y venta de animales no faenados.

2. Venta: Varios productos algunas familias destinaban sólo para venta, especialmente legumbres y especies mayores.

3. Autoconsumo: Entre $40 \%$ y $80 \%$ la producción agrícola y pecuaria se destinaba a autoconsumo, especialmente especies menores, aves, huevos y verduras. 
4. Procesamiento y venta: Al igual que el procesamiento solo, el procesamiento y venta es uno de los menores porcentajes alcanzados.

5. Procesamiento $\boldsymbol{y}$ autoconsumo: El procesamiento para el autoconsumo demuestra en mayor porcentaje, entendido como el mínimo necesario para el consumo, por ejemplo el desposte de especies menores; aquí no figura las especies mayores.

6. Venta y autoconsumo: Sube el porcentaje de hasta alrededor del 30.0 por ciento de todos los productos, excepto el de especies menores.

7. Procesamiento, venta $\boldsymbol{y}$ autoconsumo: La posibilidad de que la producción se destine para procesamiento, venta y autoconsumo es de las más bajas.

\section{Gráfico 5}

Producción y destino de alimentos

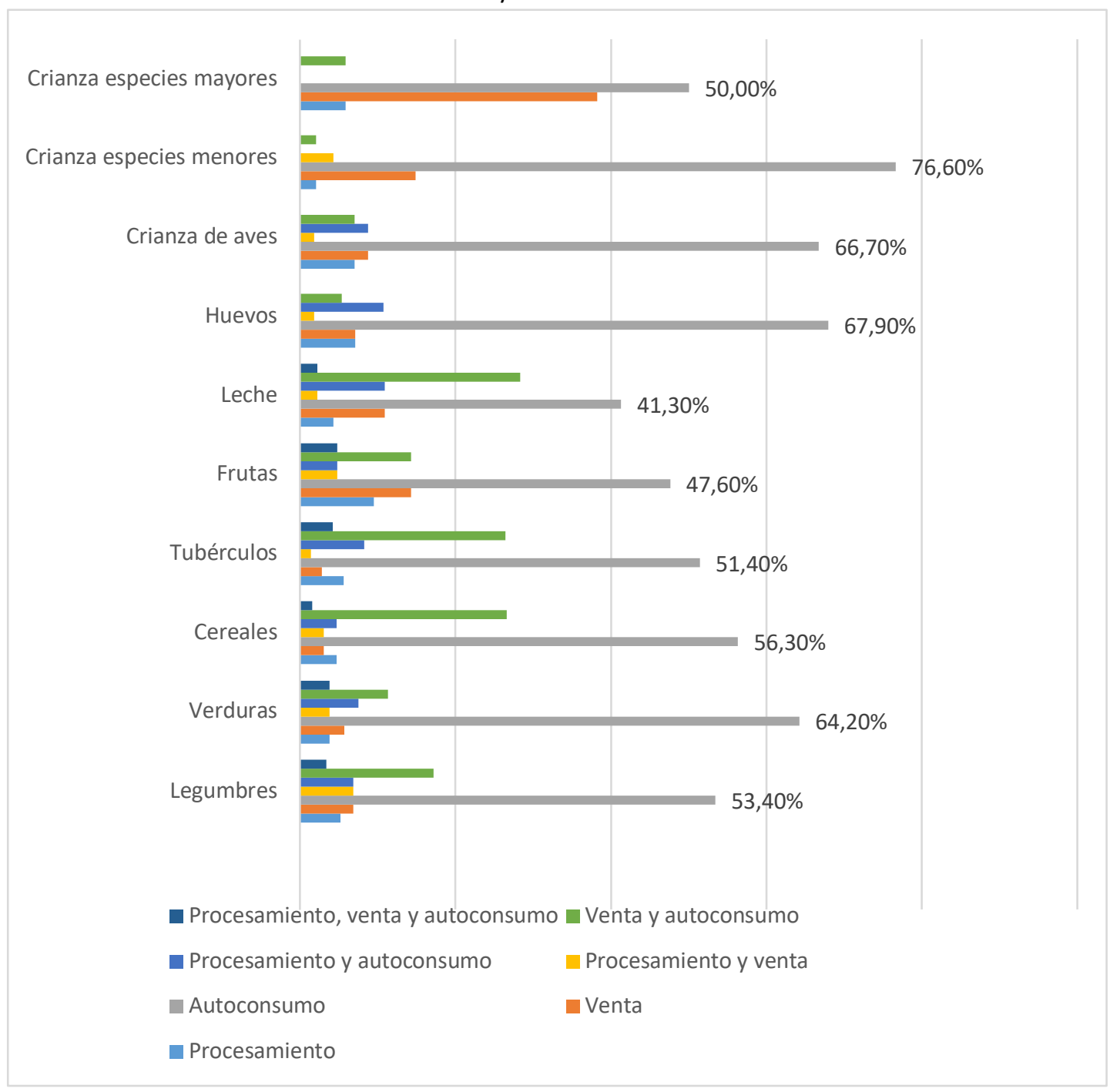

\subsection{Acceso a los alimentos}

Otro de los objetivos del presente estudio fue identificar algunos factores relacionados con el acceso a los alimentos en la población investigada, tales como alimentos que consumen diariamente, tiempos de comida, consumo de bebidas, especialmente agua, formas de preparación de los alimentos, comidas fuera del hogar y almacenamiento para emergencias. 
Los más consumidos, reporta la población investigada, fueron aquellos ricos en hidratos de carbono como cereales, tubérculos y azúcar, seguidos por aceites y margarinas; y en ese orden descendente, verduras y hortalizas, panes y fideos, luego lácteos, huevos y frutas. Alimentos que deberían estar en la mesa familiar como oleaginosas, frutas tropicales y plátanos son los porcentajes más bajos (ver gráfico 6).

Gráfico 6

Alimentos consumidos diariamente por la familia

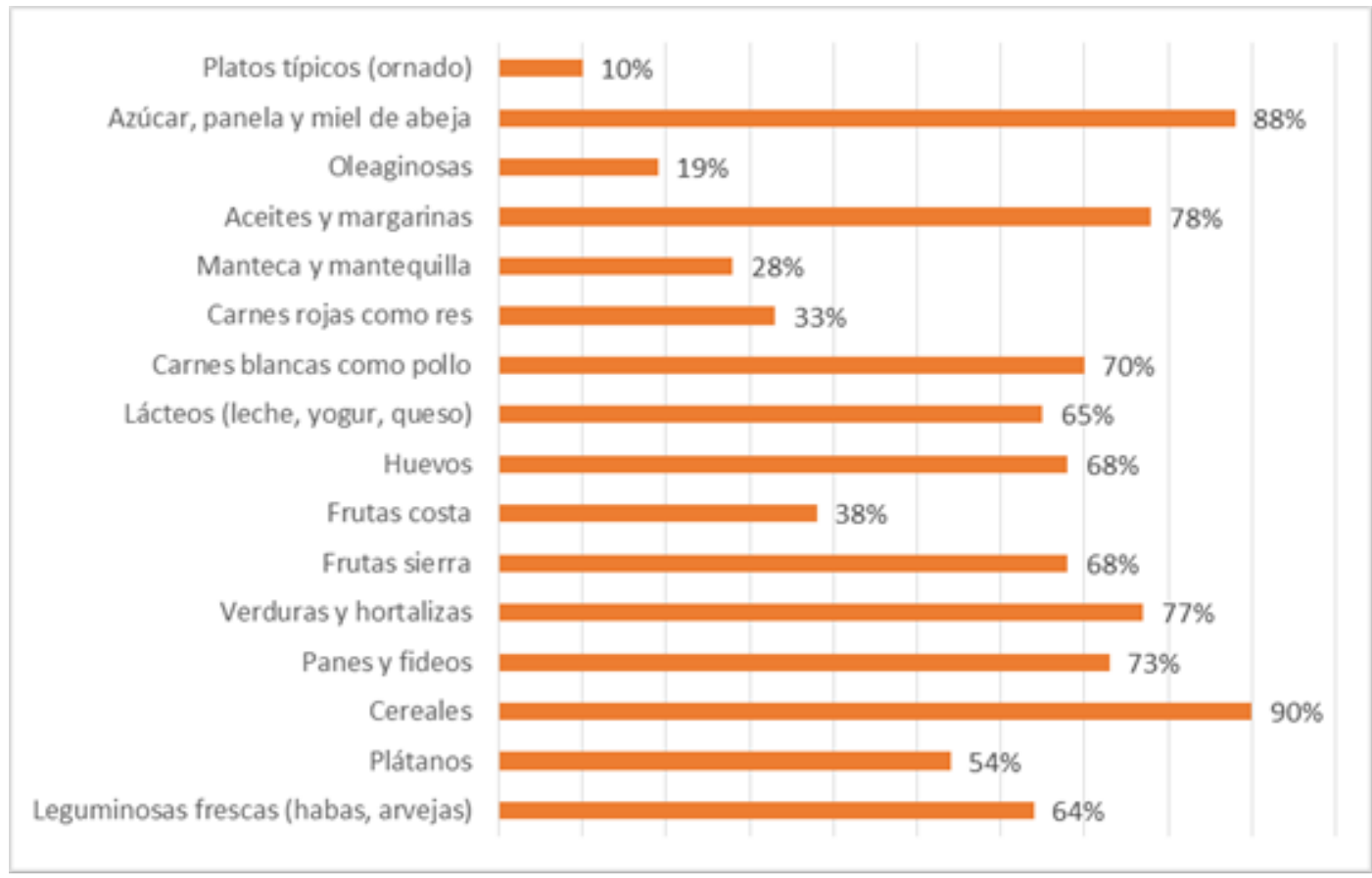

El número y variedad de los alimentos que se consumen diariamente pueden calificarse como muy adecuado, adecuado o inadecuado, porque de esto depende el estado nutricional de las personas, así como su normal funcionamiento, especialmente de su competencia inmunológica. Como se observa en la tabla 3 sólo un cuarto de las familias tenía un consumo diario de alimentos considerado como muy adecuado.

Tabla 3

Nivel de adecuación del consumo diario de alimentos

\begin{tabular}{llrrrr}
\hline & & Frecuencia & Porcentaje & \multicolumn{1}{c}{$\begin{array}{c}\text { Porcentaje } \\
\text { válido }\end{array}$} & \multicolumn{2}{c}{$\begin{array}{c}\text { Porcentaje } \\
\text { acumulado }\end{array}$} \\
\hline Válido & Inadecuado & 49 & 31,6 & 31,6 & 31,6 \\
\cline { 2 - 6 } & Adecuado & 65 & 41,9 & 41,9 & 73,5 \\
\cline { 2 - 6 } & Muy adecuado & 41 & 26,5 & 26,5 & 100,0 \\
\cline { 2 - 6 } & Total & 155 & 100,0 & 100,0 & \\
\end{tabular}

La literatura científica recomienda que el número de tiempos de comida diarias deben ser más de tres veces y que el desayuno es una de las comidas más importantes. En el estudio se encontró que la gran mayoría de familias no cena y tampoco tienen colaciones en la media mañana y la tarde. Así también la gran mayoría tiene los tres tiempos de comida más usuales desayuno, almuerzo y merienda (ver gráfico 7). De acuerdo al número de tiempos de comida sólo el $10.3 \%$ de las familias investigadas, alcanzó un nivel muy adecuado. 
Gráfico 7

Número de tiempos de comida

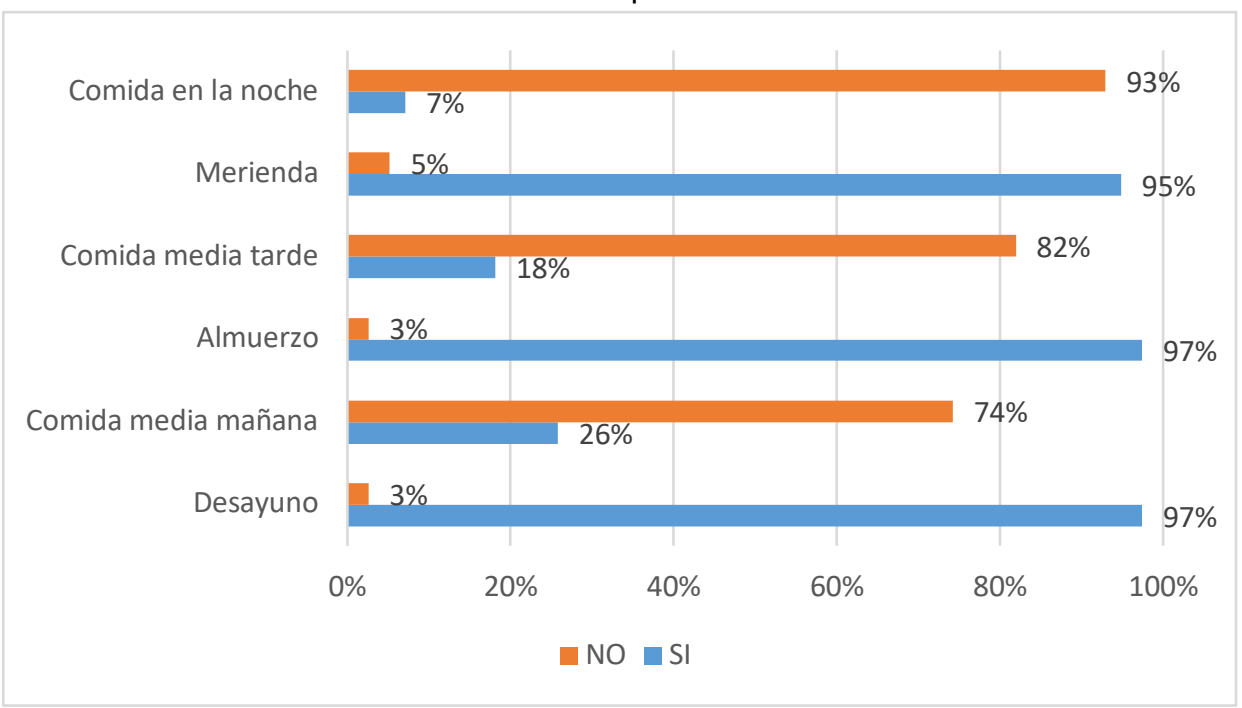

Puesto que el organismo humano está compuesto por el $60 \%$ de agua, se entiende que la ingesta diaria de ésta es indispensable para la economía orgánica. Las bebidas pueden ser ingeridas de diferentes fuentes: preparaciones culinarias como sopas, caldos, jugos, otras; además toma en cuenta el agua contenida en los alimentos y el agua pura. Se indagó sobre la preferencia de consumo de bebidas y se encontró que adecuadamente, el mayor porcentaje prefiere el agua pura y jugos naturales, en menor proporción gaseosas y agua mineral y menor aun, los jugos procesados o bebidas alcohólicas (ver gráfico 8). En acuerdo a la valoración dada en la metodología del estudio el $81 \%$ se presume tenía una ingesta adecuada de bebidas (ver gráfico 9).

\section{Gráfico 8}

Tipo de bebidas consumidas con mayor frecuencia

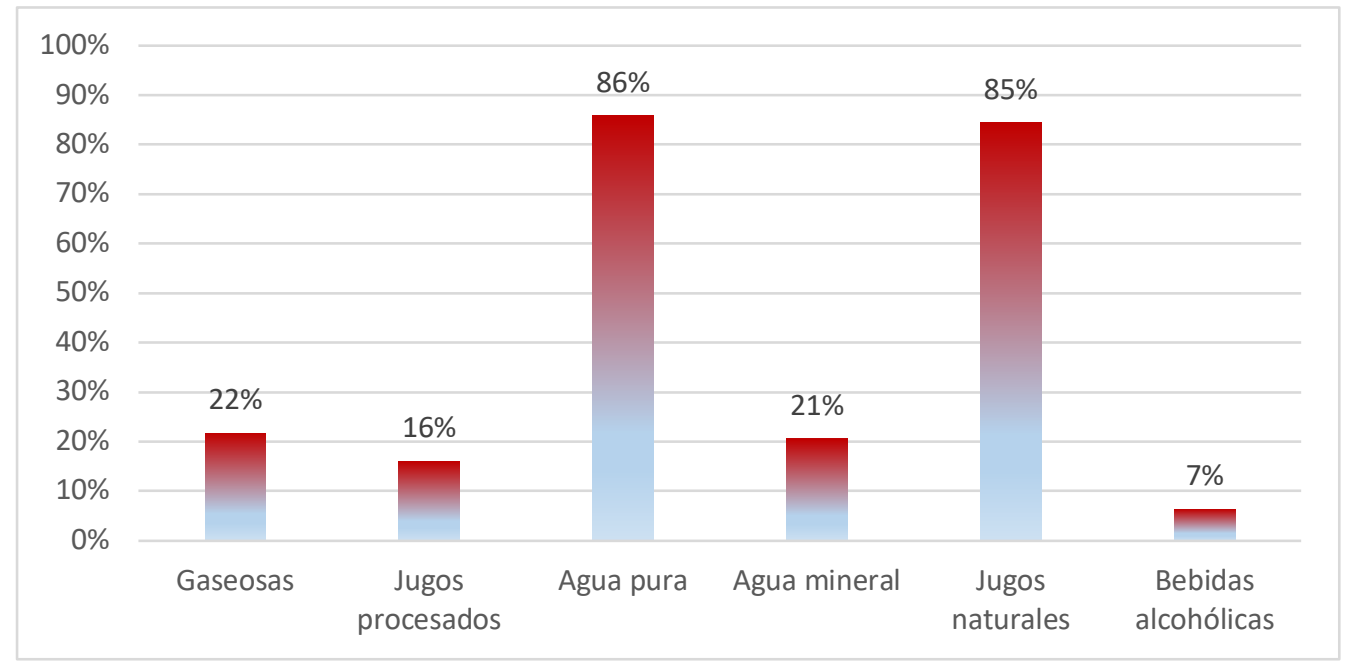


Gráfico 9

Nivel de adecuación de consumo de bebidas

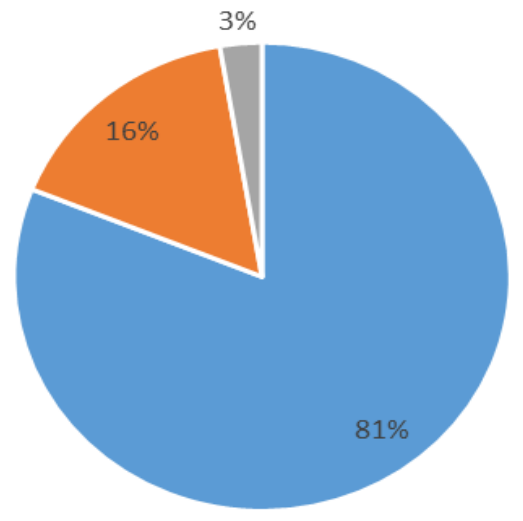

- Adecuado - Inadecuado = Muy inadecuado

El consumo recomendado de ingesta de agua de entre 6 y 8 vasos ha sido ampliamente extendido entre la población; en la tabla 4 se observó que en las familias estudiadas, un $47.1 \%$, efectivamente señalaron que los hacen, el resto se clasificó entre consumo de agua adecuado o inadecuado.

Tabla 4

Nivel de adecuación del consumo diario de agua

\begin{tabular}{llrrrr}
\hline & & Frecuencia & Porcentaje & \multicolumn{1}{c}{$\begin{array}{c}\text { Porcentaje } \\
\text { válido }\end{array}$} & \multicolumn{1}{c}{$\begin{array}{c}\text { Porcentaje } \\
\text { acumulado }\end{array}$} \\
\hline \multirow{2}{*}{ Válido } & Inadecuado & 22 & 14,2 & 14,2 & 14,2 \\
\cline { 2 - 6 } & Adecuado & 60 & 38,7 & 38,7 & 52,9 \\
\cline { 2 - 6 } & Muy adecuado & 73 & 47,1 & 47,1 & 100,0 \\
\cline { 2 - 6 } & Total & 155 & 100,0 & 100,0 & \\
\hline
\end{tabular}

Las formas de preparación de los alimentos son principios básicos del conocimiento sobre técnicas que permitan ofrecer al consumidor una comida equilibrada, inocua, que cubra las necesidades nutricionales y apetitosas; en este estudio se enfoca en que, por razones de salud, se recomienda consumir más los alimentos cocidos y crudos (como verduras y frutas) que alimentos fritos. De éstos últimos una cuarta parte contestó que es su preferencia de preparación y una tercera parte alimentos crudos (ver gráfico 10).

\section{Gráfico 10}

Formas de preparación de los alimentos más frecuentes en la familia

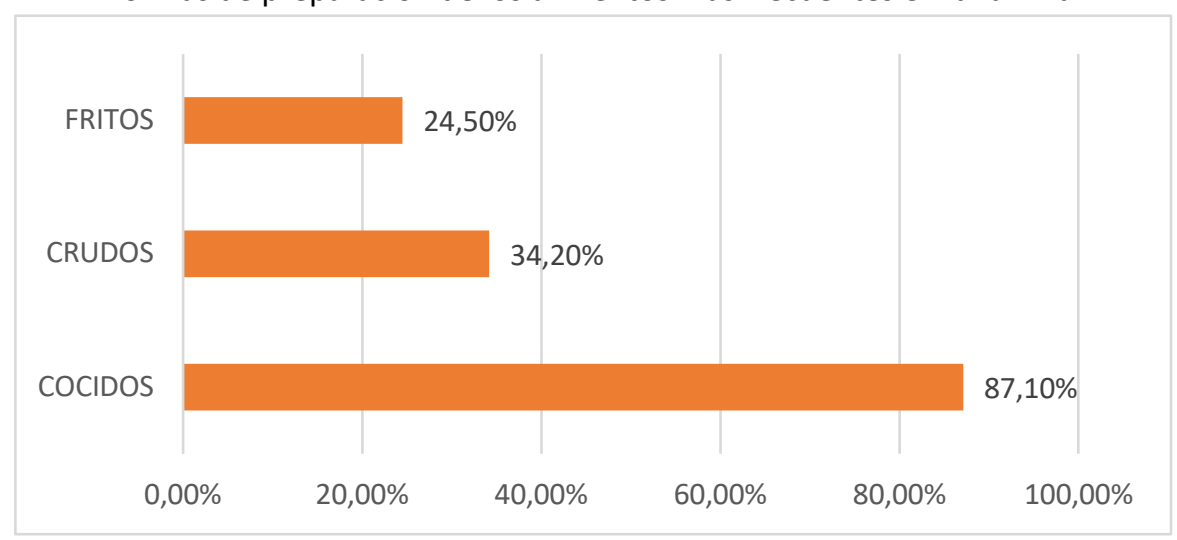


Por razones económicas, de higiene $\mathrm{y}$, sobre todo, porque las comidas fuera del hogar tienen una alta concentración en hidratos de carbono simples y en grasas, el resultado obtenido es más o menos de 50/50, pero según refiere, está más asociado a sus actividades de comercialización fuera de la parroquia de al menos una vez por semana. En cuanto a si acostumbran almacenar alimentos para casos de emergencia, el $74.2 \%$, contestó que no (ver tabla 5).

Tabla 5

Almacenamiento de alimentos en caso de emergencia

\begin{tabular}{rlrrrr}
\hline & & Frecuencia & Porcentaje & \multicolumn{1}{c}{$\begin{array}{c}\text { Porcentaje } \\
\text { válido }\end{array}$} & \multicolumn{1}{c}{$\begin{array}{c}\text { Porcentaje } \\
\text { acumulado }\end{array}$} \\
\hline \multirow{2}{*}{ Válido } & \multicolumn{1}{c}{$\mathrm{Si}$} & 40 & 25,8 & 25,8 & 25,8 \\
\cline { 2 - 6 } & No & 115 & 74,2 & 74,2 & 100,0 \\
\cline { 2 - 6 } & Total & 155 & 100,0 & 100,0 & \\
\hline
\end{tabular}

\subsection{Condiciones de salud e higiene}

Dentro del componente de seguridad alimentaria: uso y utilización biológica de los alimentos los factores elegidos en el estudio están orientados hacia las prácticas básicas de salud en las que en prospectiva se pueda acompañar a través de proyectos de intervención a la población. En condiciones de salud se abordó hábitos, atención en salud, capacitación en salud y nutrición, morbi - mortalidad; y, algunos factores alimentarios como edad de destete, alimentación complementaria y edad en la que se ofrece leche de vaca al infante.

En la sociedad se operan condiciones de comportamiento humano que suelen ser perjudiciales para la salud de los individuos pero que también repercuten en la vida familiar. Ejemplos de ellos constituyen las enfermedades crónicas y personas con algún tipo de discapacidad, se encontró el $16 \%$ y $8 \%$ respectivamente, de estos casos. Otros comportamientos que pueden ser controlados son el tabaquismo, alcoholismo y automedicación. No hubo casos de consumo de drogas (ver gráfico 11).

\section{Gráfico 11}

Hábitos y condición de salud de miembros de las familias investigadas

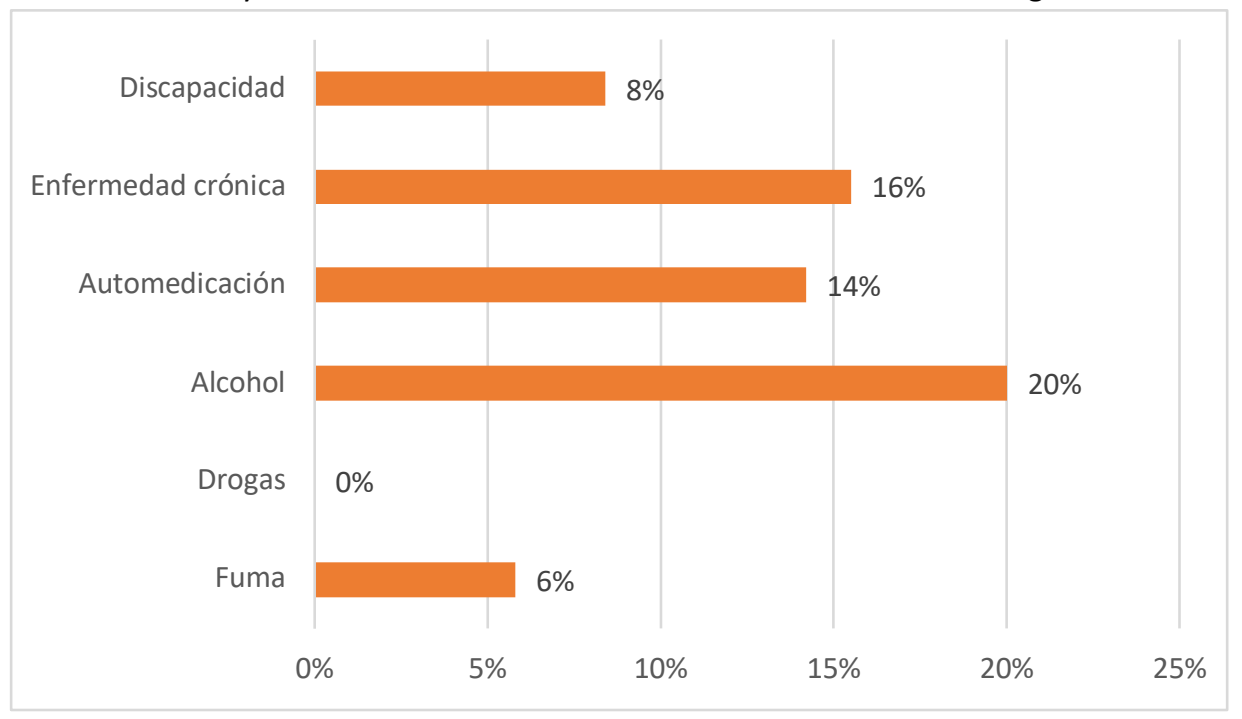

Una de las actividades humanas inherentes a toda la población del mundo, es la producción y eliminación de la basura, hecho que parecería tan cotidiano, resulta que es determinante para la sanidad del planeta. Se da por sentado que el mejor sistema es la recolección a través de sistemas municipales, pero aun dentro de ello, la 
costumbre de separar la basura orgánica de la inorgánica sería lo deseable. Enterrar o quemar la basura resulta también un problema para la salud pública (ver gráfico 12).

Gráfico 12

Eliminación y disposición de basura

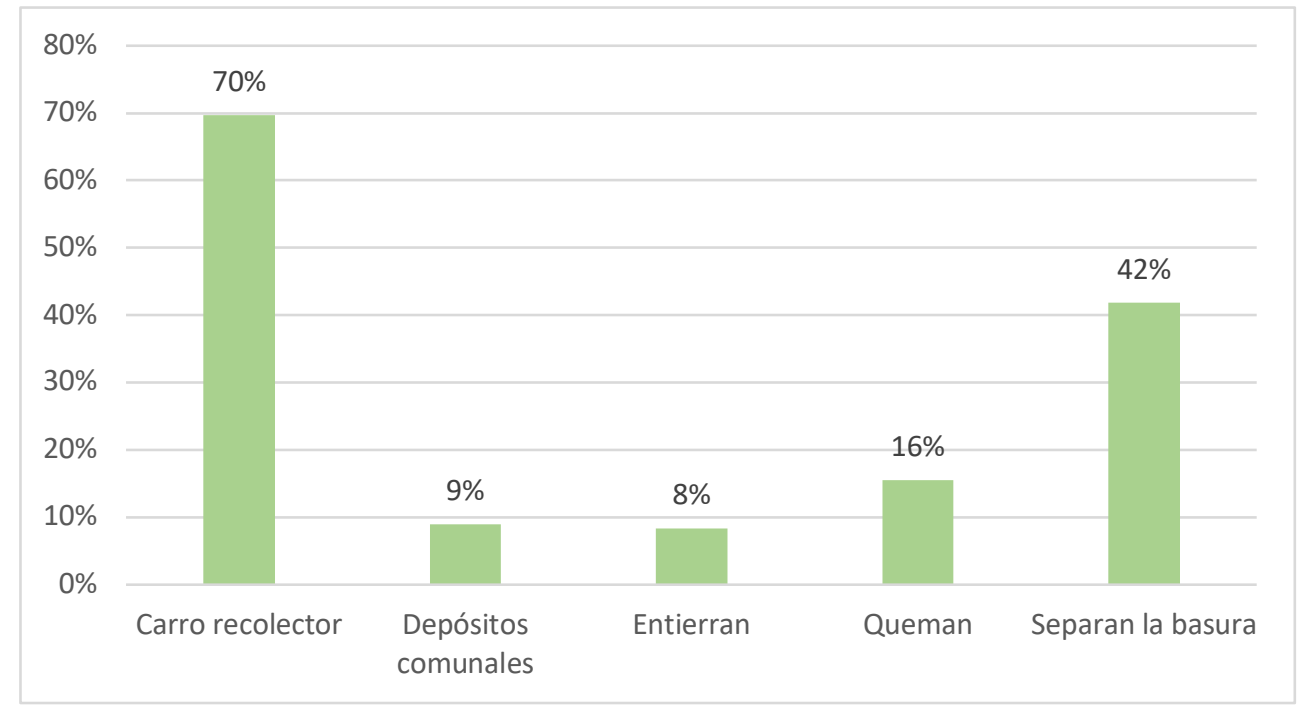

La preferencia o acceso al sistema de salud, está relacionado principalmente con la capacidad económica, con los conocimientos y tradiciones de individuos y familias; entre los más perjudiciales pueden figurar el no hacerse atender, la automedicación o los sistemas informales, en este estudio los mencionados tuvieron los porcentajes más bajos; la mayoría se atiende en el sector público o privado, no se encontró ningún miembro de la familia que sea afiliado al IESS (ver gráfico 13). Se indagó también si en el último año han recibido algún tipo de capacitación en salud y nutrición el $82 \%$, contestó que no.

\section{Gráfico 13}

Lugar de atención en salud

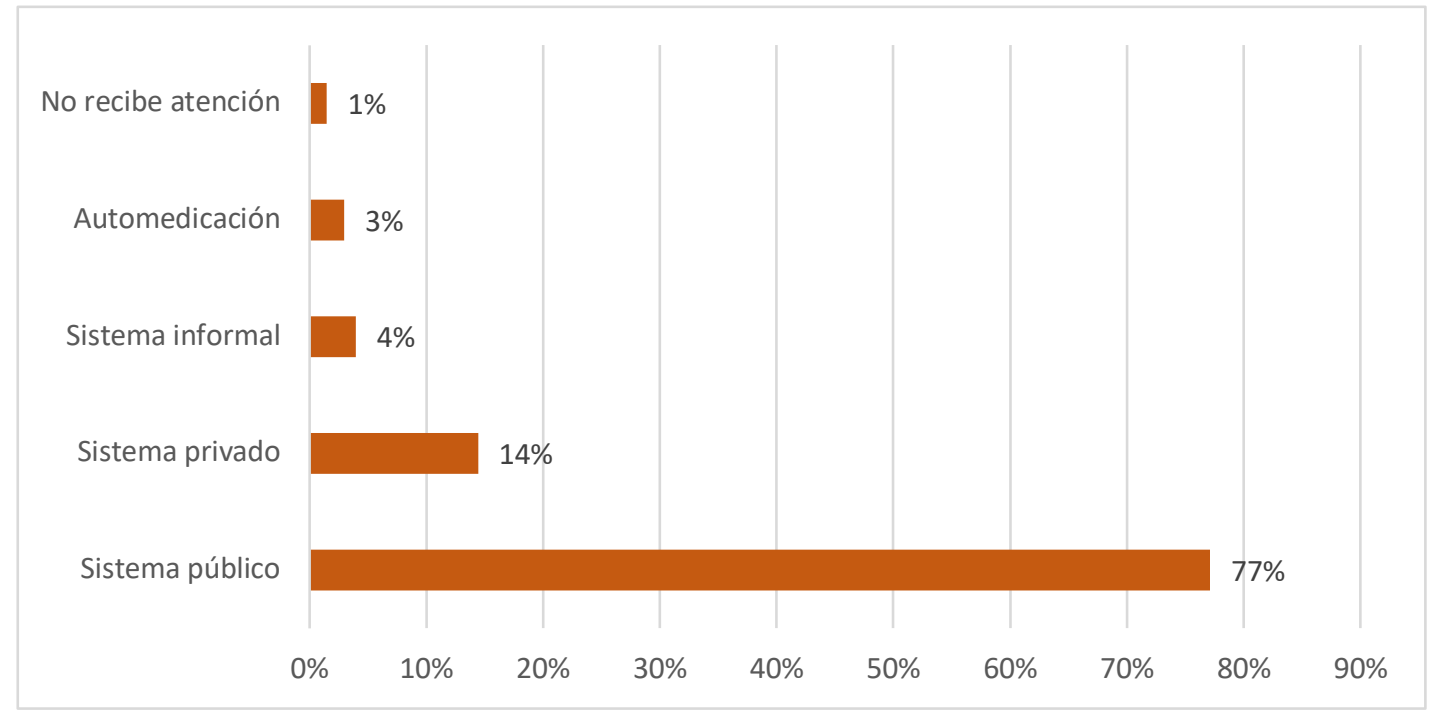

Al indagar si algún miembro de la familia había padecido de alguna enfermedad en el último mes, se encontró que aproximadamente el $50 \%$ enfrentó casos de enfermedades respiratorias y/o gastrointestinales y, si el último año alguien había fallecido, el $92 \%$ contestó que no, un $5 \%$ fue debido a enfermedades crónicas, $1 \%$ muerte materna, el resto por accidentes o enfermedades infecciosas (ver gráfico 14). 
Gráfico 14

Causas de fallecimiento

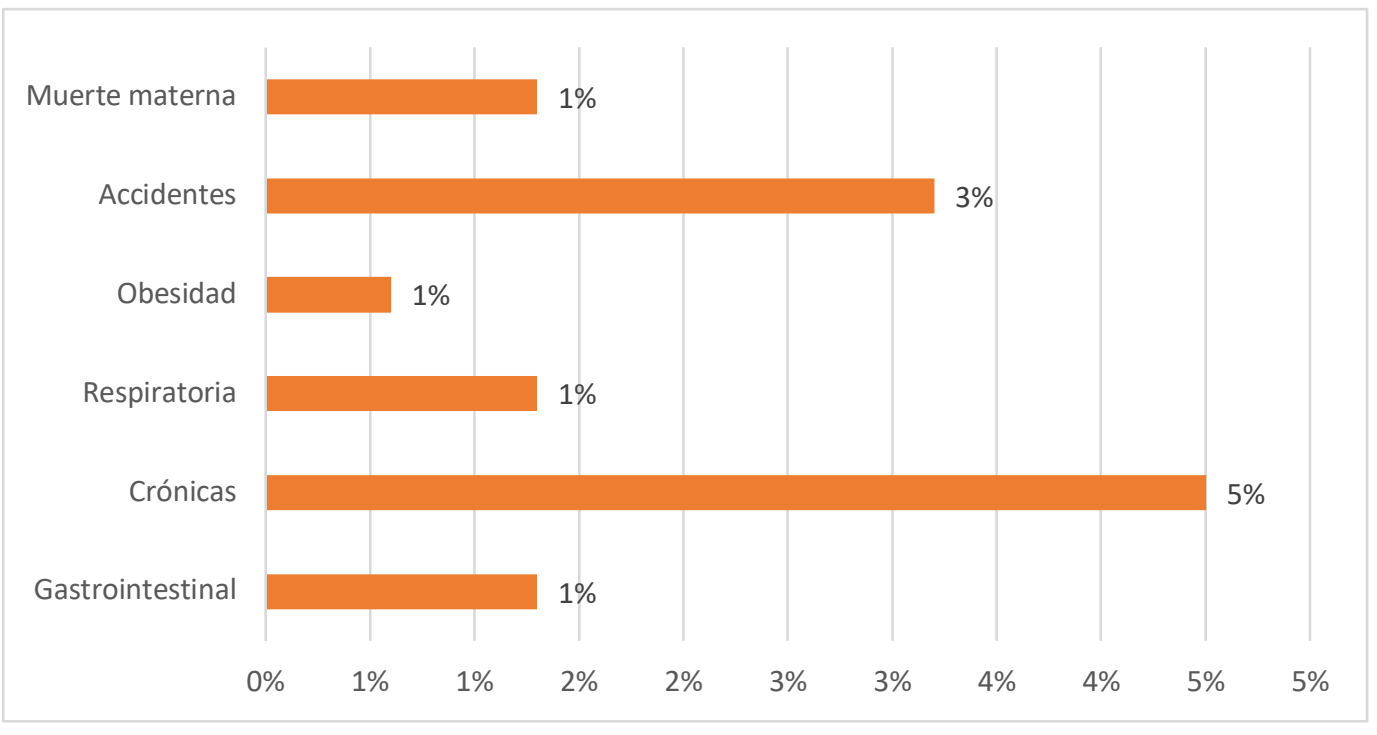

\subsection{Factores alimentarios}

De los principales factores protectores de la salud figura la lactancia materna; en el gráfico 15 más de $50 \%$ de las madres destetó a sus hijos hasta después de los 12 meses de edad.

\section{Gráfico 15}

Edad de destete

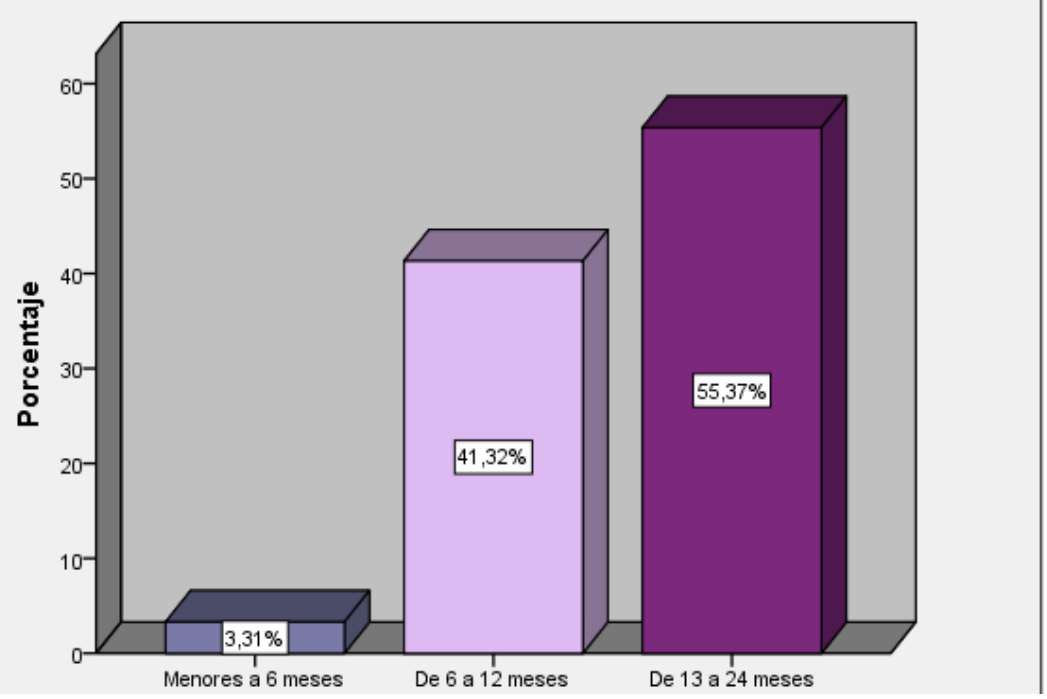

Tan importantes como la lactancia materna son los conocimientos y prácticas de destete, se encontró una gran variedad en las respuestas que permiten inferir que éste es uno de los aspectos en los cuales el personal de salud y de educación debería trabajar intensamente en beneficio de la salud de la población más vulnerable de toda sociedad (ver tabla 6). De igual manera la introducción de cualquier otro alimento que no sea la lactancia materna o artificial antes o mucho después de los seis meses afecta a la salud y desarrollo de los niños. 
Se encontró que el $11.1 \%$ lo realizaba antes de los seis meses y, el $17 \%$ después de los 13 . Además, el $41 \%$ ha dado biberón, aspecto que podría ser innecesario en madres que desarrollan su trabajo en el campo. Casi el $63 \%$ contestó que dio a sus hijos leche de vaca antes de los 12 meses de edad (ver gráfico 16).

Tabla 6

Tipo de alimentación complementaria que da al niño/a

\begin{tabular}{|c|c|c|c|c|c|}
\hline & & Frecuencia & Porcentaje & $\begin{array}{l}\text { Porcentaje } \\
\text { válido }\end{array}$ & $\begin{array}{l}\text { Porcentaje } \\
\text { acumulado }\end{array}$ \\
\hline \multirow[t]{9}{*}{ Válido } & Sopas & 13 & 8,4 & 11,4 & 11,4 \\
\hline & Pollo, carne, huevos & 3 & 1,9 & 2,6 & 14,0 \\
\hline & Papillas de frutas o verduras & 24 & 15,5 & 21,1 & 35,1 \\
\hline & $\begin{array}{l}\text { Leche de vaca, en polvo, } \\
\text { yogurt }\end{array}$ & 4 & 2,6 & 3,5 & 38,6 \\
\hline & Frutas & 14 & 9,0 & 12,3 & 50,9 \\
\hline & Coladas de avena o máchica & 54 & 34,8 & 47,4 & 98,2 \\
\hline & Agua aromática & 2 & 1,3 & 1,8 & 100,0 \\
\hline & Total & 114 & 73,5 & 100,0 & \\
\hline & Sin niños/as & 41 & 26,5 & & \\
\hline Total & & 155 & 100,0 & & \\
\hline
\end{tabular}

Gráfico 16

Edad que le dio leche de vaca al niño/a

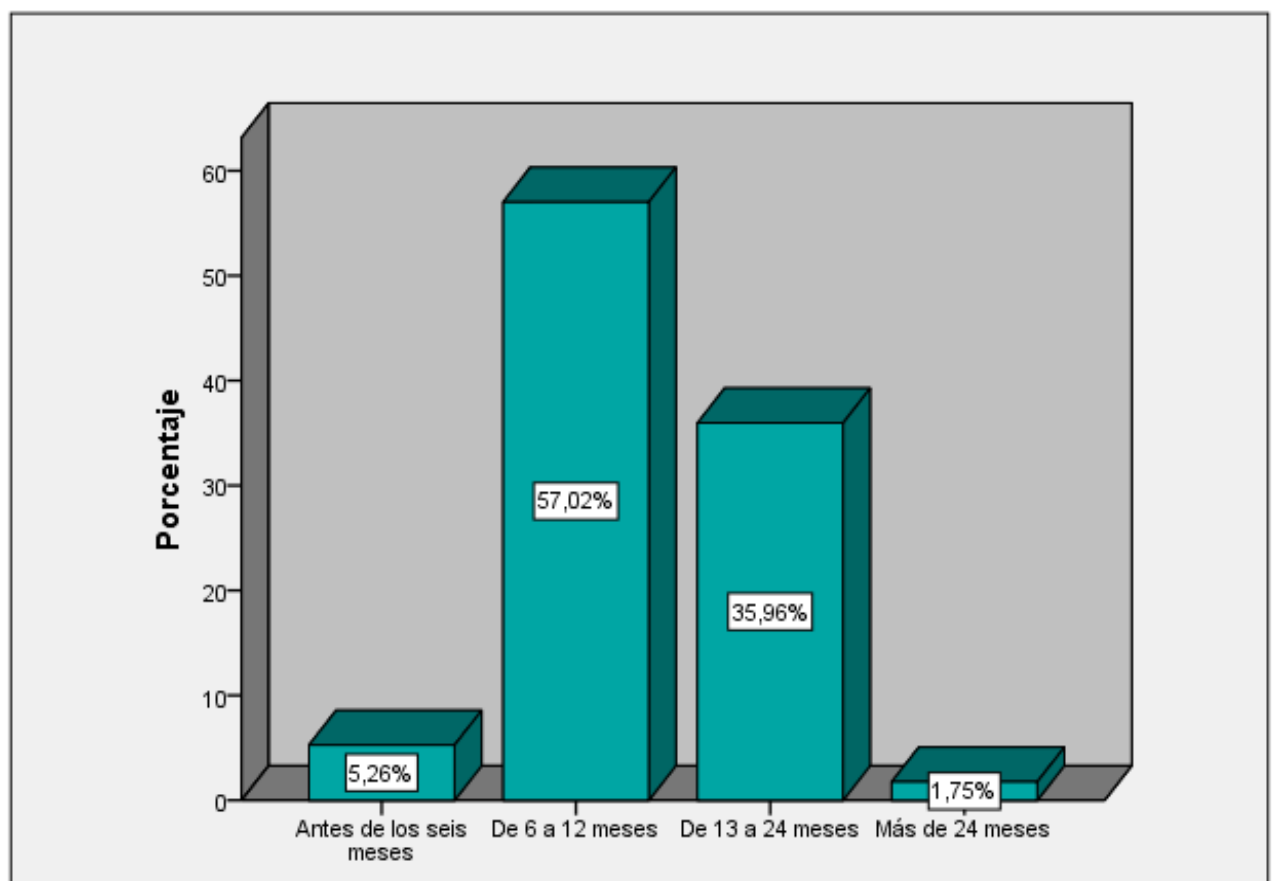

\subsection{Estabilidad en el acceso de alimentos}

Tratándose de un grupo de estudio en su mayoría de productores agrícolas se podría inferir que las temporadas de siembra y proceso de producción son las que mayor dificultad presentaría en el acceso a los alimentos, sin embargo, una cuarta parte respondió que en cualquier temporada tienen dicha dificultad (ver gráfico 17). 
Gráfico 17

Época de mayor dificultad para conseguir alimentos

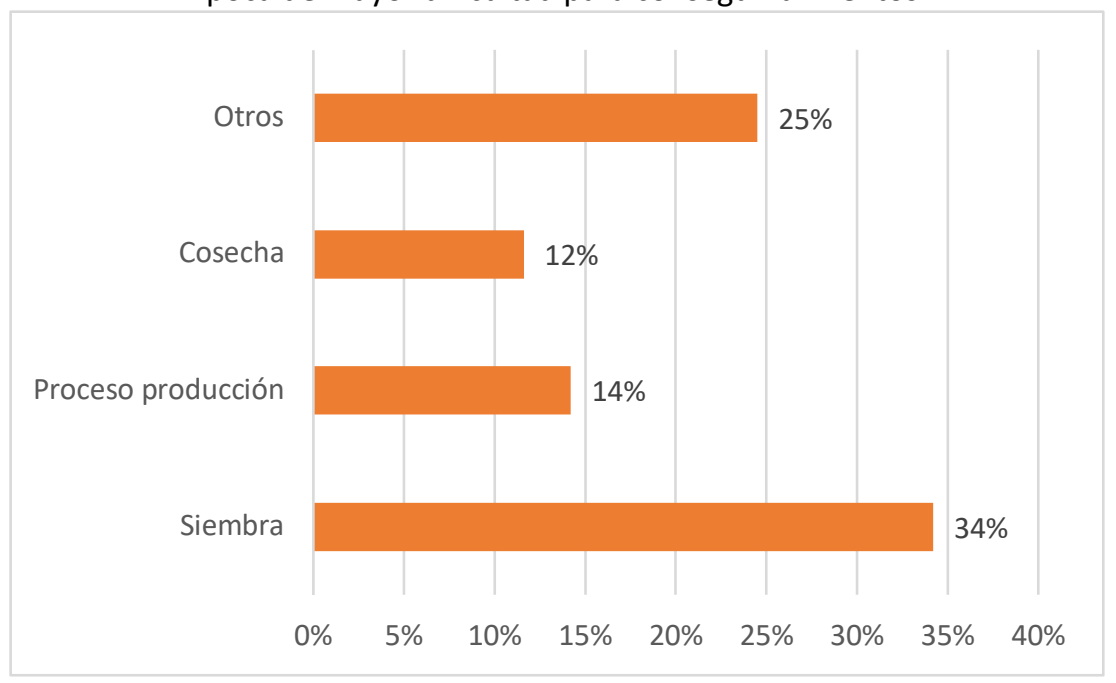

El principio básico de sobrevivencia humana es tener seguridad en el acceso diario a los alimentos; la disponibilidad por sí sola no es suficiente si no se tiene los medios para la adquisición de los mismos. El estudio arrojó que el $82 \%$ compra los alimentos, alrededor del 10\% consume lo almacenado; el resto fía y, en general, no reciben ningún tipo de ayuda alimentaria (ver tabla 7).

Un hallazgo interesante fue que al menos un $70 \%$ acostumbraba a leer las etiquetas de los productos empacados, principalmente para cerciorarse de la fecha de caducidad de los mismos; sin embargo, un $4.5 \%$ consumía los alimentos caducados porque dijeron que no les hacía daño, para que no se desperdicie, o por razones de deficiencia económica. Por último a la pregunta de si conocían sobre el semáforo nutricional, el 78\% por ciento contestó que no.

Tabla 7

Forma de adquisición de alimentos para el consumo sino existe producción

\begin{tabular}{rrrrr}
\hline & Compran & $\begin{array}{c}\text { Consume lo } \\
\text { almacenado }\end{array}$ & $\begin{array}{c}\text { Ayuda } \\
\text { alimentaria }\end{array}$ & $\begin{array}{r}\text { Fían dinero } \\
\text { o alimentos }\end{array}$ \\
\hline Frecuencia & 127 & 20 & 1 & 7 \\
\hline Porcentaje & 81,9 & 12,9 & 0,6 & 4,5 \\
\hline
\end{tabular}

Para fines de estudios etnográficos generalmente se parte de la identificación de quién es el jefe de hogar, según manifiesta el Instituto Nacional de Estadísticas y Censos (INEC), "una persona debe hacerse responsable de asumir ese rol en cada casa" y, sólo especifica que el jefe debe tener más de 15 años (Ferreira Salazar, 2008). Si el propio hogar identifica a uno de sus miembros como jefe, independientemente de su género, aporte económico o edad, para fines del presente trabajo de investigación del nivel de seguridad alimentaria de la población, la información de quién es el jefe de hogar es importante para el acercamiento, conocimiento y aprobación del mismo en la participación de su familia en el proyecto de vinculación que se ofrezca a la comunidad.

En la Encuesta Longitudinal de la Primera Infancia (ELPI) aplicada el año 2012 a un total de 2.855 madres de niños menores de 3 años, encontraron que en acuerdo a la escolaridad de la madre, ellas respondían más o menos a diferentes manifestaciones de interacción. En realidad, la gran brecha del aprendizaje no son las características de las personas a ser acompañadas (intervenidas), sino a la capacidad del facilitador para manejarse entre los 
aspectos etic y emic de la cultura, en la utilización práctica y no solo narrativa o descriptiva de las variables, sino también en determinar en el plan de intervención los aspectos visuales, auditivos y/o kinestésicos que podrían ser más efectivos para alcanzar los objetivos deseados (Rodríguez Garcés \& Muñoz Soto, 2016).

Además de la información recolectada a través de la encuesta aplicada a los jefes de hogar, se conoce que las familias tienen un promedio de 4 miembros, que disponen de los servicios indispensables y que la mayoría son viviendas de mediano riesgo. Una de las más importantes que considera el equipo técnico es la forma de almacenamiento de los alimentos y lugares en donde se alojan los equipos e insumos agrícolas, especialmente los químicos, pero también los inorgánicos. La distribución adecuada de los elementos mencionados, tienen una relación directa con la utilización biológica de los alimentos y determinados riesgos para la salud de sus habitantes. Otros estudios (Sánchez Quintanar \& Jiménez Rosas, 2010) y programas de vinculación relevan la importancia de la comprensión de la lógica de la vivienda rural, dada la complejidad de sucesos que en ella se desarrollan que van más allá de conocer las actividades agrícolas y los ecosistemas en donde se ejecutan, sino también la relaciones intrafamiliares y comunitarias que podrían frenar o potenciar su seguridad alimentaria.

Por otro lado, las estadísticas señalan que una de cada tres familias ecuatorianas viven en las áreas rurales y que 4 de cada 5 familias son pobres. A pesar de esto, las necesidades habitacionales en estas zonas son menores que en las urbanas, pero la precariedad de sus viviendas es mayor por la carencia de servicios, mala calidad de la construcción hacinamiento e inseguridad (INEC, 2014) como se observó en este estudio. La atención a las necesidades de vivienda de los sectores rurales, ya sea por razones presupuestarias o por la dispersión de los asentamientos, pobreza endémica, degradación ambiental, alta migración u otros (Pinto \& Ruiz, 2009), han sido tradicionalmente relegadas de las políticas públicas, aunque hay proyectos de homologación del bono para vivienda rural, son aspectos que salen del campo de incidencia del presente proyecto.

Por las razones mencionadas, se concibe intervenir en la problemática de la vivienda desde el punto de vista de la interculturalidad y la sustentabilidad social, económica y ambiental (Pinto \& Ruiz, 2009). Algunas de ellas que se enfocarían en el fortalecimiento del tejido social, de la convivencia interna y comunitaria para el mejor uso de servicios, especialmente en la higiene en acuerdo a lo que disponen y, en la viabilidad de lo que se podría mejorar. En las zonas de mayor concentración poblacional se encontró que agua potable, alcantarillado y recolección de basura disponen en un promedio del 70\%, el trabajo estaría enfocado en el 30\% restante. En cuanto a servicios higiénicos y cocina separada de los otros ambientes de la vivienda contaban más de $92 \%$. De forma genérica las familias con un índice de riesgo mediano y alto (95\%) serían la población objeto de posibilidades de intervención.

La indagación sobre la disponibilidad de otros servicios permite identificar los medios que se puede utilizar para llegar a la población con mensajes adecuados para su mejoramiento. El hecho de que el $96 \%$ disponga de luz eléctrica ofrece la oportunidad del diseño de actividades de capacitación, toda vez que más de $80 \%$ cuenta con radio, televisión, celulares y un 36\% de internet, que coincide con los datos de que Ecuador tenía en 2014 en conectividad a Internet un $35 \%$ de penetración. Este porcentaje ha aumentado en las zonas urbanas, pero se mantiene en las rurales (El Comercio, 2014).

Tomando en cuenta que la disponibilidad de alimentos no se centra solo en la producción, sino también en otras condiciones susceptibles de mejoramiento, sus niveles de adecuación son el resultado de factores multifactoriales en donde juegan un papel importante los expertos en el campo pertinente a las actividades de producción, transformación y comercialización de productos agropecuarios. El papel que ataña a los Nutricionistas, y en este proyecto en particular, es trabajar en los resultados de su ámbito y alcance; por ejemplo, incentivar al consumo de grupos de alimentos energéticos como cereales y tubérculos que ayuden a alcanzar el mayor porcentaje posible de los requerimientos energéticos; el consumo o producción de legumbres, sino para la venta, para el uso familiar, que mejoren el acceso de proteínas; promover el consumo de verduras, hortalizas 
y frutas, de éstas últimas, por su contribución energética, de vitaminas y minerales cualquier variedad de plátanos, que se conoce que no los cultivan pero que son asequibles económicamente; y, mayor consumo, al menos tres veces por semana de los alimentos de origen animal como huevos, aves, leche o carne de especies menores.

Otros factores que pueden ser modificados desde el ámbito de la academia es acompañar a la comunidad en procesos de almacenamiento y procesamiento de los alimentos para las épocas de escasez, en la elección más efectiva de los lugares de compra; y, el destino que se da a la producción. Según el presente estudio hay productos, especialmente de origen animal, que sólo lo destinan a la venta. En el supuesto ideal que exista una adecuada disponibilidad de alimentos, el componente de la seguridad alimentaria acceso, en poblaciones de bajo nivel económico, constituye una de las principales causas de inseguridad alimentaria.

Se ha definido al acceso a los alimentos como la capacidad de los hogares/individuos de adquirir una cantidad suficiente de alimentos y que ésta deber ser suficiente inocua y nutritiva. El acceso a los alimentos depende de los precios, de la capacidad de compra por parte de la población, de los patrones de consumo o hábitos alimentarios. La carencia de acceso puede ser económica: pobreza, altos precios de los alimentos, falta de créditos y física: deficientes carreteras e infraestructura de mercado (FAO. FIDA. OPS. WFP y UNICEF, 2020).

Dentro de este componente, es relevante el consumo, que además de estar asociado con la baja capacidad de compra, está con los niveles de conocimiento, especialmente de las madres de familia de una alimentación adecuada, independientemente de lo que puedan adquirir o producir. Para el presente proyecto constituye prioritario enfocar la intervención a los principales problemas encontrados y que pueden ser abordados desde las potencialidades académicas de profesores, estudiantes e institución. De acuerdo a la disponibilidad y preferencia de consumo de alimentos, es posible modular algunos aspectos como el exceso de consumo de alimentos hidrocarbonados azúcares y cereales, aumentar el consumo de verduras, hortalizas y frutas, incentivar al consumo o producción de legumbres secas y frescas y oleaginosas; e, incrementar el consumo de alimentos fuente de proteínas. Por otro lado, se puede mejorar brindando alternativas para el incremento del número de comidas diarias, especialmente para los niños, señalando que lo recomendado es que las comidas sean distribuidas a lo largo del día en al menos cuatro diarias.

Puesto que el organismo humano está compuesto por el $60 \%$ de agua, se entiende que la ingesta diaria de ésta es indispensable para la economía orgánica, por lo que sería aconsejable realizar una comprobación de los resultados de la encuesta para dar alternativas de consumo de agua segura para todos los miembros de la familia, subrayando en la disminución del consumo, que es apreciable del porcentaje, de jugos procesados, gaseosas y bebidas alcohólicas.

En el acápite correspondiente a condiciones de salud e higiene lo más relevante que se encontró es que hay un porcentaje apreciable de miembros de la familia con enfermedades crónicas o con algún tipo de discapacidad, quienes requieren atención especial para el cuidado de su dieta, higiene y terapia; otros comportamiento susceptibles de apoyo son el tabaquismo, alcoholismo y automedicación; a su vez, se debe intervenir en la forma de eliminación de la basura, en el manejo de fertilizantes y pesticidas tanto inorgánicos como orgánicos y en la eliminación en el ambiente de líquidos lixiviados.

Aparentemente, tienen acceso al sistema de salud público, y un porcentaje muy pequeño, prefiere hacerse atender a través de métodos de medicina tradicional. Prevalece, según la encuesta, un alto porcentaje de casos de morbilidad en el mes anterior a la misma, principalmente de enfermedades respiratorias y gastrointestinales. Las principales causas de mortalidad fueron las enfermedades crónicas, los accidentes y hubo una muerte materna en el año anterior a la encuesta. 
Desde el campo alimentario - nutricional relacionando con las causas de morbi-mortalidad, factores de los componentes de la seguridad alimentaria como el consumo y utilización biológica de los alimentos serían prioritarios para la intervención, porque la higiene individual, del hogar y de la comunidad; una dieta adecuada, variada y equilibrada; $y$, una correcta hidratación con agua segura, son los mayores potenciadores del sistema inmunológico que es la principal fuente de defensa del organismo ante las injurias externas a las que está abocado. En este estudio se encontró que independientemente de la edad de la madre, la mitad del grupo destetó a sus hijos hasta después de los 12 meses de edad, la otra mitad lo hizo antes, que la introducción de cualquier otro tipo de alimento que no sea leche materna lo hizo antes o mucho después de los seis meses de edad, más de la tercera parte dio biberón que al estar siempre con sus hijos podría evitarlo; y, leche de vaca el $63 \%$ la administró antes de los 12 meses de edad. Por último la alimentación complementaria es tan variada, que constituiría para el proyecto de vinculación uno de los puntos más vastos para intervenir.

La dinámica agrícola y pecuaria en relación a la estabilidad en el acceso a los alimentos podría ir de suficiencia a escasez, dependiendo de las épocas de siembra, proceso de producción y cosecha, sin embargo, una cuarta parte de las respuestas fueron que tienen dificultad para conseguir alimentos durante todas las temporadas. Como gestionan entonces el tema de su alimentación, la gran mayoría comprando de acuerdo a su capacidad económica, fiando o consumiendo los alimentos que pueden almacenar.

\section{Conclusiones}

Los resultados de este estudio diagnóstico permitirán determinar, de acuerdo a la magnitud y/o letalidad de los problemas encontrados, el modo de intervención requerido en cada caso. Si la magnitud y letalidad de algunos problemas son bajas, no se intervendrá; pero si la magnitud y/o letalidad son medias o altas, se intervendrá de forma inmediata, mediata o a largo plazo o una combinación de todas ellas. Por otro lado, en acuerdo a las causas identificadas de los problemas, se determinará el tipo de intervención.

A manera de ejemplo, no se intervendrá en los niveles formales de educación de la madre. De forma inmediata y a través de actividades de capacitación directa a las mujeres, se abordará sobre lactancia y alimentación en el primer año de vida. De forma mediata y mediante talleres y visitas a los hogares, se acompañará a la población beneficiaria en aspectos relacionados con higiene personal, familiar y de la comunidad. A largo plazo, el ejercicio de determinación de los mejores métodos para cambiar comportamientos reñidos con la salud y bienestar, se replicarán en otros espacios geográficos similares, así como también la publicación de esta experiencia será un aporte al conocimiento científico y social.

\section{Referencias bibliográficas}

Calero León, C. J. (2011). Seguridad alimentaria en Ecuador desde un enfoque de acceso a alimentos. (Ediciones Abya - Yala (ed.); 1era-edic ed.). Recuperado de https://biblio.flacsoandes.edu.ec/catalog/resGet.php?resld=52065

El Comercio. (2014). Ecuador ocupa el octavo puesto en la región en penetración de Internet. El Comercio, Actualidad. Recuperado de https://www.elcomercio.com/actualidad/internet-ecuador-tecnologiaconectividad-uit.html

FAO. FIDA. OPS. WFP y UNICEF. (2020). Panorama de la seguridad alimentaria y la nutrición en América Latina y el Caribe.

FAO. (2020). Estadísticas sobre Seguridad Alimentaria. Organización de Las Naciones Unidas Para La Alimentación y La Agricultura. Estadística. Recuperado de http://www.fao.org/economic/ess/ess-fs/es/ 
FAO. (2021). Seguridad alimentaria y nutrición para todos. Seguridad Alimentaria y Nutrición Para Todos. Recuperado de http://www.fao.org/food-security-and-nutrition-for-all/es/

Ferreira Salazar, C. (2008). Composicion de hogares ecuatorianos. Estudio comparativo censos 1990-2001. In Instituto Nacional de Estadistica y Censos Ecuador. Recuperado de https://www.ecuadorencifras.gob.ec/documentos/web-inec/Bibliotecas/Estudios/Estudios_Sociodemograficos/Composicion_Hogares_Ecuatorianos_1990-2001.pdf

Freire, W. B., Ramírez, M. J., Belmont, P., Mendieta, M. J., Silva, K. M., Romero, N., Sáenz, K., Pamela, P., Gómez, L. F., \& Monge, R. (2013). Encuesta Nacional de Salud y Nutrición. ENSANUT-ECU 2011-2013.

INEC. (2014). Informe de Resultados sobre la Encuesta de Condiciones de Vida (ECV) 2013 - 2014. Recuperado de https://www.ecuadorencifras.gob.ec//documentos/web-inec/ECV/ECV_2015/documentos/150411 ResultadosECV (2).pdf

Ministerio de Coordinación de Desarrollo Social. FAO. (2011). Seguridad alimentaria y nutricional en el Ecuador. Construyendo la Soberanía Alimentaria. In A. Adoum (Ed.), Iniciativa de America Latina y el Caribe sin hambre (pp. 1-346). Recuperado de http://www.fao.org/3/y8705s/y8705s00.pdf

Observatorio Social del Ecuador. (2019). Situación de la niñez y adolescencia en Ecuador. 32,33,156. Recuperado de https://www.eluniverso.com/sites/default/files/archivos/2019/02/infome_de_la_unicef.pdf

OPS/OMS. (2020). Panorama de la seguridad alimentaria y nutricional. OPS_OMS Ecuador. Recuperado de https://www.paho.org/ecu/index.php?option=com_content\&view=article\&id=1864:panorama-de-laseguridad-alimentaria-y-nutricional\&Itemid=360

Pinto, V., \& Ruiz, S. (2009). Vivienda Rural en el Ecuador desafíos para procesos sustentables e influyentes. In Flacsoandes.Edu.Ec (Primera ed). Centro de investigaciones Ciudad. Recuperado de https://biblio.flacsoandes.edu.ec/shared/biblio_view.php?bibid=114490\&tab=opac

Programa Especial para la Seguridad Alimentaria-PESA-Centroamérica. Proyecto Food Facility Honduras. (2011). Seguridad Alimentaria y Nutricional. Conceptos básicos. In Seguridad Alimentaria y Nutricional. Conceptos básicos. (pp. 1-8). https://doi.org/10.2307/j.ctv18dvt8h

Ramírez, R., \& Ramírez Gallegos, F. (2002). Versiones y aversiones del desarrollo (F. Ramírez Gallegos (ed.); Primera Ed). Universidad Andina Simón Bolívar. Recuperado de https://biblio.flacsoandes.edu.ec/catalog/resGet.php?resld=45321

Rodríguez Garcés, C., \& Muñoz Soto, J. (2016). Calidad Educativa del Ambiente Familiar y Escolaridad Materna. Paradígma, 37(1), 76-98.

Sánchez Quintanar, C., \& Jiménez Rosas, E. O. (2010). Vivienda rural. Su complejidad desde distintas disciplinas. Revista Lunazul, 30(30), 174-196.

\section{(cc) $\mathrm{BY}-\mathrm{NC}$}

Esta obra está bajo una Licencia Creative Commons

Atribución-NoComercial 4.0 Internacional 